\title{
Congrès annuel de la Société française et francophone de chirurgie de l'obésité et des maladies métaboliques (SOFFCO-M)
}

Nice, 12 et 13 février 2010

Le congrès annuel de la SOFFCO se déroulera du vendredi 12 février 2010 à 8 h 00 au samedi 13 février 2010 à 13 h 00 à Nice, Hôtel « Le Méridien », 1, Promenade des Anglais, F-06000 Nice, France

Parmi les sujets abordés :

- les procédures et leurs résultats : anneau, sleeve, courtcircuit gastrique, diversion biliopancréatique ;

- la chirurgie métabolique, une nouvelle voie de recherche pour le diabète ;

- les nouvelles approches mini-invasives ;

- les communications libres et les vidéos sur la prise en charge médicochirurgicale.

\author{
Hôtel Le Méridien \\ 1, Promenade des Anglais, F-06000 Nice, France \\ Organisation scientifique : \\ Pr J. Mouiel \\ 40, boulevard Victor-Hugo, \\ F-06000 Nice, France \\ Tél. : +334931611 15 \\ Fax : +33493162151 \\ E-mail : pr.mouiel@wanadoo.fr \\ Inscriptions : \\ TRADOTEL \\ 14, avenue Marianna, F-06000 Nice, France \\ Tél. : +33493530010 \\ Fax : +33493530039 \\ E-mail : muriel@tradotel-riviera.com
}

